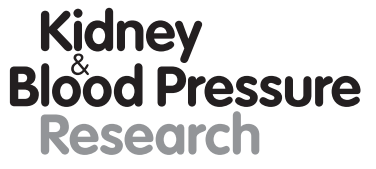

\title{
COVID-19, Low-Molecular-Weight Heparin, and Hemodialysis
}

\author{
Alessandra F. Perna ${ }^{a}$ Giovanna Capolongo $^{a}$ Francesco Trepiccione $^{a}$ \\ Mariadelina Simeoni ${ }^{a} \quad$ Miriam Zacchia $^{a}$ Diego Ingrosso ${ }^{b}$ \\ aDepartment of Medical Translational Sciences, University of Campania Luigi Vanvitelli,

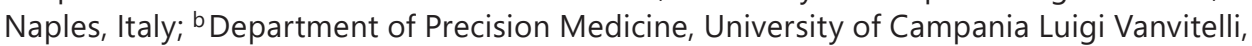 \\ Naples, Italy
}

\author{
Keywords \\ COVID-19 $\cdot$ Low-molecular-weight heparin $\cdot$ Hemodialysis
}

\section{Are Hemodialysis Patients at a Lower Risk for COVID-19 Infection?}

Hemodialysis patients are a population displaying impaired lymphocyte and granulocyte function, and, by strict definition, they are, at least theoretically, at an increased risk for infection by COVID-19 given also the characteristics of the average dialysis center, where social distancing is difficult to achieve $[1,2]$.

However, the scant available data indicate somewhat otherwise; in a report from a university dialysis facility (Zhongnan Hospital) in Wuhan, China, with 201 patients, the prevalence was equal to 5 (2.5\%). In addition, cases had no severe symptoms or died [3].

According to another report, related to another university dialysis facility (Renmin Hospital) in Wuhan, China, in the period between January 14, 2020, when the first confirmed case was diagnosed, and February 17, 2020, when the epidemic was declared extinct, among 230 hemodialysis patients 37 (16\%) COVID-19 cases were diagnosed. During the epidemic, 7 hemodialysis patients died (18.9\%). Symptoms were mild in most surviving patients and there were no cases admitted to the intensive care unit. Laboratory exams showed an impaired cellular immune function (especially lymphocytes of $\mathrm{T}$ cells, Th cells, killer T cells, and NK cells) and an incapability of mounting the "cytokine storm" linked to pneumonia, compared to COVID-19 patients not on hemodialysis. The cause of death was related instead to cardiovascular complications [4]. 


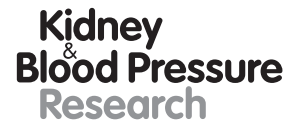

Research \begin{tabular}{l|l}
\hline Kidney Blood Press Res 2020;45:357-362 \\
\hline DOI: 10.1159/000508460 & $\begin{array}{l}\text { @ 2020 The Author(s). Published by S. Karger AG, Basel } \\
\text { www.karger.com/kbr }\end{array}$ \\
\hline
\end{tabular}

Perna et al.: COVID-19 and HD

In an Italian experience, among 200 patients 18 were infected and isolated (9\%), and in another unit of 170 patients only 4 were infected [5]. In the Piedmont and Aosta regions, among 2,893 patients 98 were infected (3.4\%) during the first month of the epidemic [6]. By the way, in none of the mentioned studies was the mode of anticoagulation during hemodialysis mentioned. While they cast doubts on the open-space hospital model now implemented in many hospitals, which is incompatible with the need to counteract epidemics [7], these reports also create uncertainty regarding the concept that these patients are at a particularly increased risk for COVID-19.

\section{Hemodialysis and Anticoagulation}

Heparin actually consists of a heterogeneous mixture of sulfomucopolysaccharides, containing also a minimum peptide component of 2 amino acids (glycine and serine). Heparin exerts a binding capacity to both the endothelial surface and various plasmaproteins (Fig. 1). The molecular weight range of unfractionated heparin (UFH) is 5,000-30,000. Low-molecularweight heparin (LMWH) fractions effectively inhibit the activated factor X (Factor $\mathrm{X}_{\mathrm{a}}$ ), while exerting a less inhibitory effect on thrombin, compared to the unfractionated forms. It has been shown that LMWH preparations retain their efficacy toward thromboembolisms and, compared to UFH, show increased bioavailability and the need for less frequent administration. Heparin biological activity crucially depends on the endogenous antithrombin anticoagulant $[8,9]$. The serine protease inhibitor activity of antithrombin is exerted toward thrombin and Factor $X_{a}$, resulting in the inhibition of both (Fig. 1) [10]. Congenital or acquired antithrombin deficiency is indeed associated with a high risk of thromboembolic complications and an impaired interaction with heparin. Administration of antithrombin is generally indicated for the prophylaxis of thromboembolic accidents in nephrology (e.g., in patients with nephrotic syndrome) [11]. In addition, it has been shown that during sepsis activation of the extrinsic coagulation pathway, together with a relevant decline of both coagulation inhibition and fibrinolytic mechanisms, may result in a procoagulant state, leading to microvascular thrombosis and multiorgan dysfunction [12]. Antithrombin levels decrease in sepsis and, when low, may predict high mortality [13]. In addition, heparin is utilized in this context, also for its immunomodulatory and anti-inflammatory role [14].

During hemodialysis it is necessary to perform anticoagulation of the dialysis circuit to avoid blood clotting in the system due to Factor VII, platelet, and leukocyte activation. Anticoagulation is usually performed utilizing heparin, often in Western Europe in the lowmolecular-weight form $[15,16]$, which has some advantages over UFH. Relative to UFH, in fact, LMWH could induce less undesired bleeding after completion of the dialysis session and perhaps less triglyceride reduction.

\section{Evaluating the Risk of Heparin-Induced Thrombocytopenia}

Heparin-induced thrombocytopenia (HIT) is an immune complex-mediated condition defined as a decrease in platelet counts below 150,000 per $\mathrm{mm}^{3}$, with a median nadir of about 55,000 per $\mathrm{mm}^{3}$, associated with a positive test for heparin-dependent antibodies $[17,18]$. The typical onset pattern $(60 \%$ of the cases) results in a platelet decline $5-10$ days after exposure. The rapid onset pattern (30\% of cases) occurs right after the exposure. The delayed onset pattern $(\sim 10 \%)$ occurs 9.2 days after the start of heparin administration therapy, on average, although signs and symptoms may occur up to 3 weeks after the exposure [18]. 

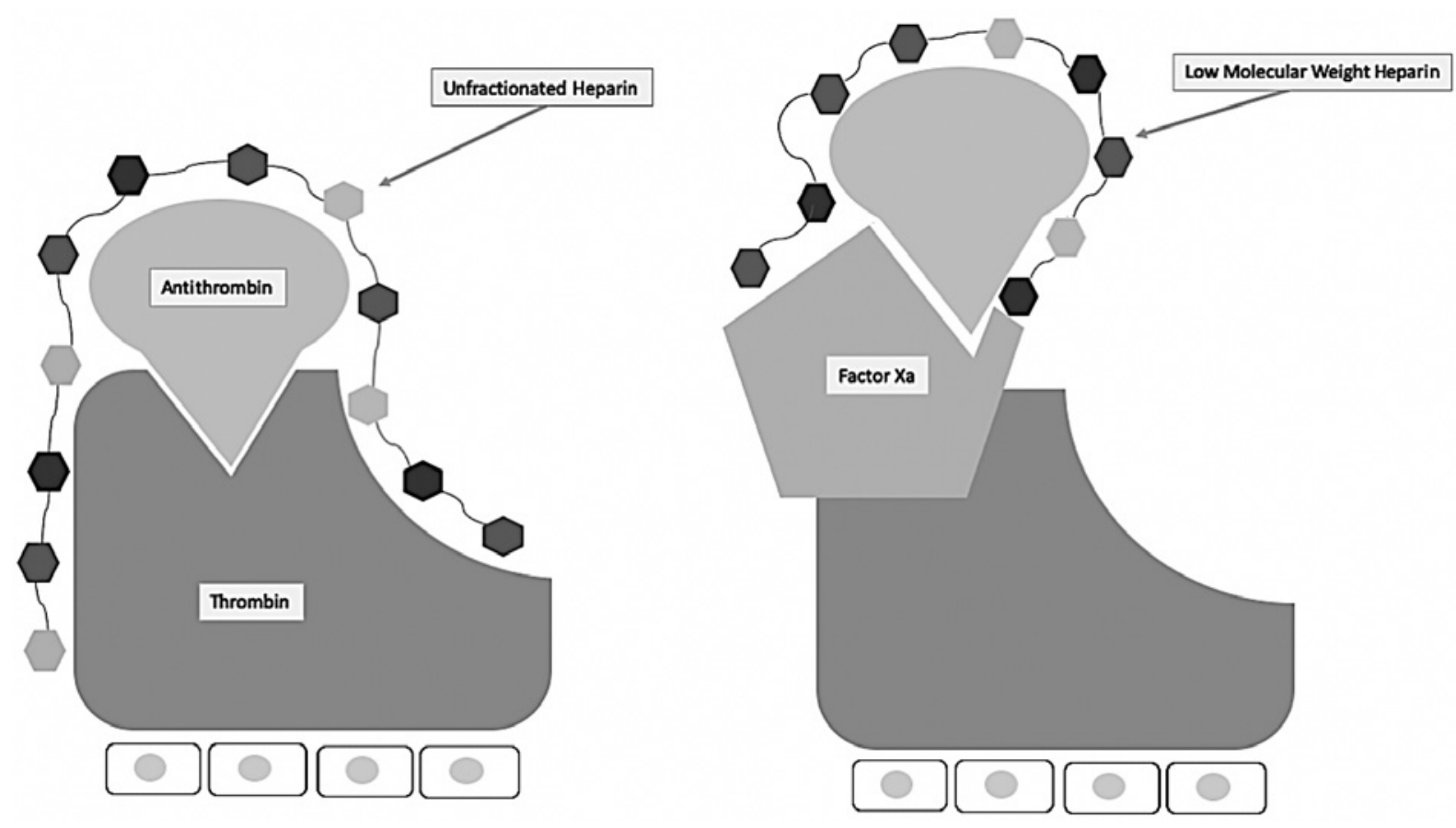

Fig. 1. Mechanism of action of UFH and LMWH with the major ligand-binding interactions involved. One of the key proteins for the activity of heparin is antithrombin, a serine protease inhibitor (SERPINSC1) that inactivates several clotting factors. Mechanistically, heparin binds to antithrombin, thus exposing the antithrombin protease inhibitor binding site and forming equimolecular complexes with its ligands. Antithrombin uses unique and extensive conformational change mechanisms to inhibit its protease ligands [8]. Heparin increases by orders of magnitude the tendency of antithrombin to interact with a number of plasma proteins. The resulting complex, in particular with thrombin (factor IIa) and factors IXa, Xia, and Xa, inhibits the protease activities of these clotting factors. Heparin indeed works as an antithrombin-protease-inhibiting cofactor without being consumed, and, once the antithrombin-protease complex is formed, heparin is released in its intact conformation, thus repeatedly activating new antithrombin molecules. Heparin biological activity crucially depends indeed on the endogenous antithrombin anticoagulant activity. The role of antithrombin is pivotal in coagulation regulation by shifting thrombin from procoagulant to anticoagulant activity. The presence of heparin dramatically increases the complex stability of antithrombin with the above-mentioned coagulation factors $[8,9]$. One important difference between UFH and LMWH is that the interaction of antithrombin with UHF almost equally induces inhibition and degradation of both Xa and thrombin, while LMWH preferentially determines degradation of factor Xa. Various other potential benefits of heparin in COVID-19 have been put forward recently [28].

Careful evaluation and monitoring should be indeed applied toward the risk of HIT [19]. LMWH offers the advantage of a reduced binding to platelet factor 4, thus decreasing the HIT risk [20]. On the other hand, the shorter size of LMWH may hamper the effectiveness of protamine as an antidote [20]. Useful information is provided by reporting a thrombocyte count of less than $50 \%$, which represents an important red flag $[19,20]$. Laboratory tests can then be used to confirm the presence of platelet factor 4 (PF4)/heparin antibodies [21]. Attention should be payed when reporting the presence of activating antibodies against PF4-heparin complexes (PF4-H) to the cut-off point for a positive test (e.g., $1 \mathrm{U} / \mathrm{mL}$ ) [19]. A score has been developed based on 8 clinical features, each scoring between -2 and +3 [22]. Other scoring systems are also available [18]. 


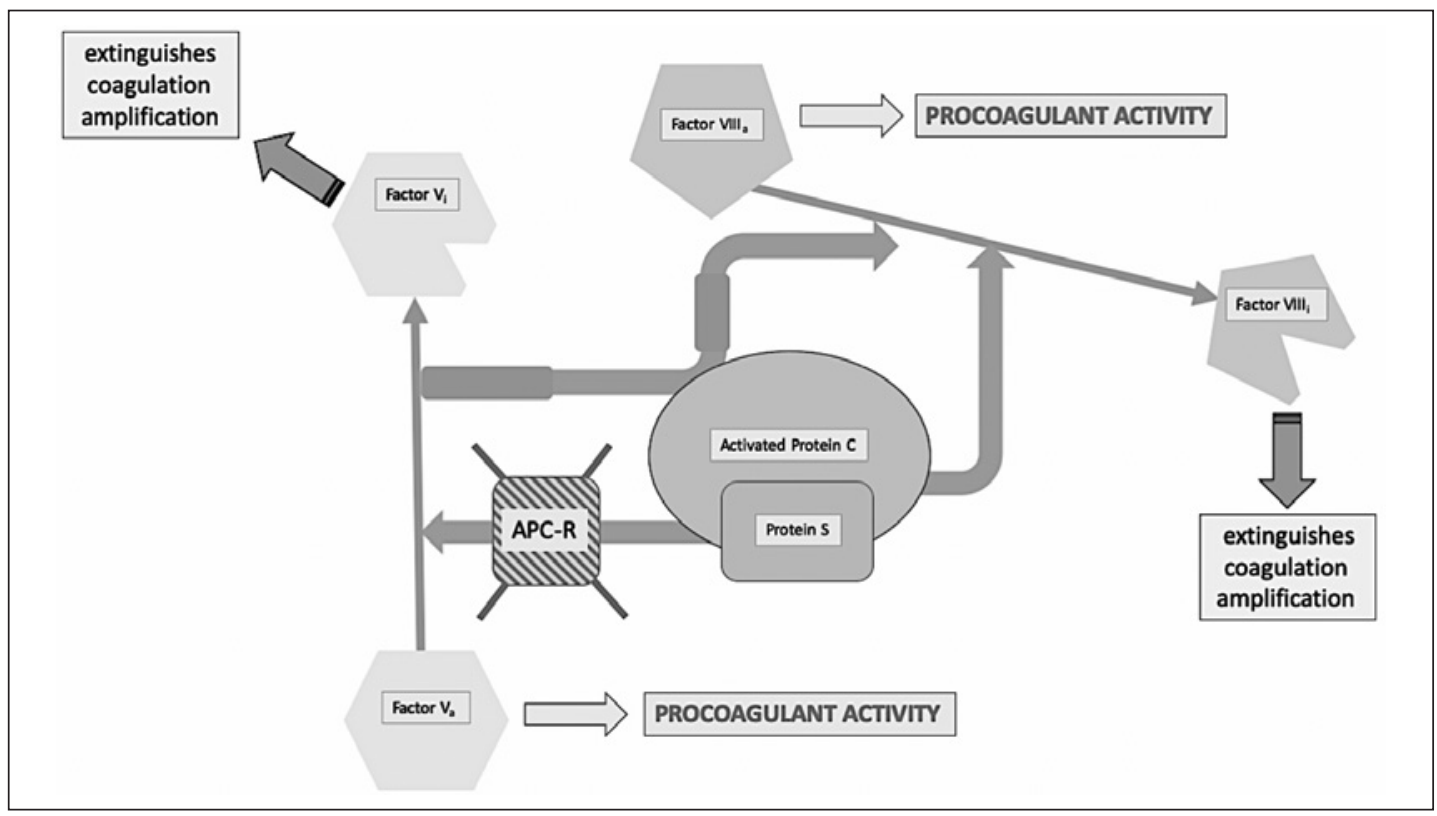

Fig. 2. Scheme of the anticoagulant activity of the protein $\mathrm{C}$ anticoagulant pathway. Protein $\mathrm{C}$ is activated by thrombin (not shown), forming APC [29]. Protein S in turn is a cofactor of APC for the inactivation of activated coagulation factors VIII $_{\mathrm{a}}$ and $\mathrm{V}_{\mathrm{a}}$. Only free protein $\mathrm{S}$, i.e., the fraction which is not bound to C4b-binding protein (not shown) in circulation, retains its anticoagulant activity. Activated factor $\mathrm{V}$ (factor $\mathrm{V}_{\mathrm{a}}$ ) procoagulant activity is inactivated by APC-catalyzed cleavage at the Arg506 level, yielding factor $\mathrm{V}_{\mathrm{i}}$. Beyond its intrinsic procoagulant activity, Factor $\mathrm{V}_{\mathrm{a}}$ also exerts an anticoagulant activity as a cofactor for APC and protein $\mathrm{S}$, in inactivation of the procoagulant factor $\mathrm{VIII}_{\mathrm{a}}$ yielding factor $\mathrm{VIII}_{\mathrm{i}}$ [30]. This function is also compromised in the presence of factor V resistance to cleavage by APC (APC-R; hatched box), mainly due to the Arg506Gln mutation (factor $\mathrm{V}_{\text {Leiden }}$ ), which indeed represents the most common cause of APC resistance in the population.

\section{LMWH and COVID-19}

LMWH has some antiviral properties in vitro and it is routinely used in COVID-19 patients to prevent or circumvent the activation of the coagulation cascade induced by inflammation [23]. This is a particularly severe and lethal complication, leading to disseminated intravascular coagulation and venous thromboembolism. In a retrospective study, LMWH therapy reduced interleukin- 6 release and activity, which is responsible of the "cytokine storm," and treated patients had also a higher percentage of lymphocytes [24]. LMWH therapy is also associated with better outcomes in severe COVID-19 patients with sepsis-induced coagulopathy and markedly elevated D-dimer levels [25].

It should be pointed out that uremia offers a unique microenvironment in which the coagulation and anticoagulation balance can be dysregulated in many ways. For example, the presence of anti-protein C and anti-protein S antibodies has been detected [26], which may critically underscore the acute onset of a procoagulant situation in these patients (already characterized by an increased thrombotic risk). These data indeed may prudentially pose the indication of monitoring protein $\mathrm{C}$ and free protein $\mathrm{S}$ (Fig. 2). It can be hypothesized that, upon SARS-Cov-2 infection, the presence of antibodies with potential inhibitory activity on protein $\mathrm{C}$ and protein $\mathrm{S}$ may even increase the functional effect of an activated protein C (APC) resistance condition, whereas already present in the patient. Testing for APC resistance is indeed advised in these patients. 


\section{Research}

Perna et al.: COVID-19 and HD

Table 1. Proposed laboratory test profile to monitor LMWH therapy and the risk of adverse reactions

\begin{tabular}{llc}
\hline Test & Rationale/purpose & References \\
\hline aPTT & Intrinsic and common coagulation pathway & 19 \\
Antithrombin & 1 & 20 \\
Platelet count $^{2}$ & Involved in heparin activity and Xa binding & 19,20 \\
HIT $^{2}$ & Adverse effect monitoring (HIT) & $19-22$ \\
D-dimer & Antibodies against PF4-H complexes & 23 \\
Anti-Factor $\mathrm{X}_{\mathrm{a}}$ activity assay & Clot degradation products & 27 \\
\hline
\end{tabular}

${ }^{1}$ Antithrombin effects are explained in Fig. 1. ${ }^{2}$ Heparin-induced thrombocytopenia is defined as a decrease in platelet count below 150,000 per $\mathrm{mm}^{3}$, with a median nadir of 55,000 per $\mathrm{mm}^{3}$, starting 5 or more days after the beginning of heparin administration, associated with a positive test for heparin-dependent antibodies $[17,18]$.

\section{COVID-19, LMWH, and Hemodialysis: Future Perspectives}

It is therefore possible that hemodialysis patients could be protected with respect to COVID-19 virus infection by the LMWH used in every hemodialysis session. We propose monitoring, in these patients, of the Anti-Factor Xa activity assay [27], as well as antithrombin, and D-dimer levels, and not just aPTT, in order to possibly even increase the LMWH dosage, in this pandemic period (Table 1).

The availability of these exams could therefore lead to optimization of LMWH in this patient population.

\section{Disclosure Statement}

A.F.P. and D.I. received funding from Gnosis, SpA, and EUTox.

\section{Funding Sources}

None.

\section{Author Contributions}

All of the authors contributed equally to the writing of this paper.

\section{References}

1 Dalrymple LS, Go AS. Epidemiology of acute infections among patients with chronic kidney disease. Clin J Am Soc Nephrol. 2008 Sep;3(5):1487-93.

2 Dalrymple LS, Mu Y, Nguyen DV, Romano PS, Chertow GM, Grimes B, et al. Risk factors for infection-related hospitalization in in-center hemodialysis. Clin J Am Soc Nephrol. 2015 Dec;10(12):2170-80.

3 Wang R, Liao C, He H, Hu C, Wei Z, Hong Z, et al. COVID-19 in hemodialysis patients: a report of 5 cases. Am J Kidney Dis. 2020 Mar;S0272-6386(20)30612-0.

4 Ma Y, Diao B, Lv X, Zhu J, Liang W, Liu L, Bu W, Cheng H, Zhang S, Yng L, Shi M, Ding G, Shen B, Wang H. 2019 novel coronavirus disease in hemodialysis (HD) patients: Report from one hd center in Wuhan, China. medRxiv preprint 2020, doi: https://doi.org/https://doi.org/10.1101/2020.02.24.20027201-y. 


\section{Kidney

Perna et al.: COVID-19 and HD

5 Rombolà G, Heidempergher M, Pedrini L, Farina M, Aucella F, Messa P, et al. Practical indications for the prevention and management of SARS-CoV-2 in ambulatory dialysis patients: lessons from the first phase of the epidemics in Lombardy. J Nephrol. 2020 Apr;33(2):193-6.

6 Manganaro M, Baldovino S; Working group of the Piedmont and Aosta Valley Section of the SIN. First considerations on the SARS-COV-2 epidemic in the dialysis units of Piedmont and Aosta Valley, Northern Italy. J Nephrol. 2020 Jun;33(3):393-395.

7 Piccoli GB. Hospitals as health factories and the coronavirus epidemic. J Nephrol. 2020 Apr;33(2):189-91.

8 Law RH, Zhang Q, McGowan S, Buckle AM, Silverman GA, Wong W, et al. An overview of the serpin superfamily. Genome Biol. 2006;7(5):216.

9 Bruce D, Perry DJ, Borg JY, Carrell RW, Wardell MR. Thromboembolic disease due to thermolabile conformational changes of antithrombin Rouen-VI (187 Asn $\rightarrow$ Asp). J Clin Invest. 1994 Dec;94(6):2265-74.

10 Perry DJ, Carrell RW. Molecular genetics of human antithrombin deficiency. Hum Mutat. 1996;7(1):7-22.

11 Zaffanello M, Brugnara M, Fanos V, Franchini M. Prophylaxis with AT III for thromboembolism in nephrotic syndrome: why should it be done? Int Urol Nephrol. 2009;41(3):713-6.

12 Samra N, AlGhwass M, Elgawhary S, Hassan M, Bekhit O, Mohamed W, et al. Serum Level of Antithrombin III (ATIII) Could Serve as a Prognostic Biomarker in Neonatal Sepsis. Fetal Pediatr Pathol. 2019 Aug;38(4):290-8.

13 Lauterbach R, Pawlik D, Radziszewska R, Woźniak J, Rytlewski K. Plasma antithrombin III and protein C levels in early recognition of late-onset sepsis in newborns. Eur J Pediatr. 2006 Sep;165(9):585-9.

14 Li X, Ma X. The role of heparin in sepsis: much more than just an anticoagulant. Br J Haematol. 2017 Nov; 179(3):389-98.

15 Ouseph R, Ward RA. Anticoagulation for intermittent hemodialysis. Semin Dial. 2000 May-Jun;13(3):181-7.

16 Skagerlind MS, Stegmayr BG. An evaluation of four modes of low-dose anticoagulation during intermittent haemodialysis. Eur J Clin Pharmacol. 2018 Mar;74(3):267-74.

17 Warkentin TE, Levine MN, Hirsh J, Horsewood P, Roberts RS, Gent M, et al. Heparin-induced thrombocytopenia in patients treated with low-molecular-weight heparin or unfractionated heparin. N Engl J Med. 1995 May; 332(20):1330-5.

18 Salter BS, Weiner MM, Trinh MA, Heller J, Evans AS, Adams DH, et al. Heparin-Induced Thrombocytopenia: A Comprehensive Clinical Review. J Am Coll Cardiol. 2016 May;67(21):2519-32.

19 Watson H, Davidson S, Keeling D. Guidelines on the diagnosis and management of heparin-induced thrombocytopenia: second edition. Br J Haematol. 2012;159:528-540.

20 Onishi A, St Ange K, Dordick JS, Linhardt RJ. Heparin and anticoagulation. Frontiers in Bioscience. Landmark. 2016 Jun;21:1372-92.

21 Martel N, Lee J, Wells PS. Risk for heparin-induced thrombocytopenia with unfractionated and low-molecularweight heparin thromboprophylaxis: a meta-analysis. Blood. 2005 Oct;106(8):2710-5.

22 Cuker A, Arepally G, Crowther MA, Rice L, Datko F, Hook K, et al. The HIT Expert Probability (HEP) Score: a novel pre-test probability model for heparin-induced thrombocytopenia based on broad expert opinion. J Thromb Haemost. 2010 Dec;8(12):2642-50.

23 Lin L, Lu L, Cao W, Li T. Hypothesis for potential pathogenesis of SARS-CoV-2 infection-a review of immune changes in patients with viral pneumonia. Emerg Microbes Infect. 2020 Dec;9(1):727-32.

24 Shi C, Wang C, Wang H, Yang C, Cai F, Zeng F, Cheng F, Liu Y, Zhou T, Deng B, Li J, Zhang Y. Clinical observations of low molecular weight heparin in relieving inflammation in COVID-19 patients: A retrospective cohort study. medRxiv 2020,doi:https://doi.org/https://doi.org/10.1101/2020.03.28.20046144.

25 Tang N, Bai H, Chen X, Gong J, Li D, Sun Z. Anticoagulant treatment is associated with decreased mortality in severe coronavirus disease 2019 patients with coagulopathy. J Thromb Haemost. 2020 May;18(5):1094-9.

26 Molino D, De Lucia D, Marotta R, Perna A, Lombardi C, Cirillo M, et al. In uremia, plasma levels of anti-protein $\mathrm{C}$ and anti-protein $S$ antibodies are associated with thrombosis. Kidney Int. 2005 Sep;68(3):1223-9.

27 Egan G, Ensom MH. Measuring anti-factor xa activity to monitor low-molecular-weight heparin in obesity: a critical review. Can J Hosp Pharm. 2015 Jan-Feb;68(1):33-47.

28 Thachil J. The versatile heparin in COVID-19. J Thromb Haemost. 2020 May;18(5):1020-2.

29 Esmon CT, Owen WG. Identification of an endothelial cell cofactor for thrombin-catalyzed activation of protein C. Proc Natl Acad Sci USA. 1981 Apr;78(4):2249-52.

30 Cramer TJ, Griffin JH, Gale AJ, Factor V. Factor V is an anticoagulant cofactor for activated protein C during inactivation of factor Va. Pathophysiol Haemost Thromb. 2010;37(1):17-23. 